\title{
Seasonal behavior of meteor radar winds over Wuhan
}

\author{
Guangxin Zhao ${ }^{1,2,3}$, Libo Liu ${ }^{1}$, Weixing Wan ${ }^{1}$, Baiqi Ning ${ }^{1}$, and Jiangang Xiong ${ }^{1}$ \\ ${ }^{1}$ Division of Geomagnetism and Space Physics, Institute of Geology and Geophysics, Chinese Academy of Sciences, Beijing, 100029, China \\ ${ }^{2}$ Wuhan Institute of Physics and Mathematics, CAS, Wuhan, 430071, China \\ ${ }^{3}$ Graduate School of the Chinese Academy of Sciences
}

(Received March 23, 2004; Revised November 9, 2004; Accepted November 10, 2004)

\begin{abstract}
A newly installed meteor radar has been installed to measure winds in the mesosphere and lower thermosphere (MLT) over Wuhan $\left(114.4^{\circ} \mathrm{E}, 30.6^{\circ} \mathrm{N}\right)$. In the present study, a database of the first 25 months (February 2002February 2004) of observations has been analyzed to investigate the climatology of mean winds and tides. The daily average zonal wind is charactered by a strong shear in solstices and an intense eastward flow in summer. The daily average meridional wind is northward in winter and southward in other seasons. There are some discrepancies between the radar mean winds and the HWM93 model winds. The summer zonal winds and meridional winds from the model are obviously weaker than our observations. The analysis on tides indicates that the diurnal tide is dominant at Wuhan. The seasonal variability is observed in both the diurnal and semidiurnal tidal amplitudes with the maximum values occurring usually near the equinoxes. Compared with the Global Scale Wave Model (GSWM00), the observed results generally show a smaller diurnal tidal amplitude and a larger semidiurnal tidal amplitude.
\end{abstract}

Key words: Meteor radar, mean winds, tides, MLT dynamics.

\section{Introduction}

Over decades, ground-based and satellite-based measurements have greatly improved our understanding of the dynamics of the mesosphere/lower thermosphere (MLT) region, but there are still many problems unsolved and the MLT region is still a focus of increasing scientific interest. A major limitation in such works is the asymmetric network of ground-based observation systems. Until recently, the majority of MLT region observations were from middle to high latitude stations in the North American and European sectors, and there are more or less deficiencies in other regions. In particular, there is a notable absence in the African and Chinese sectors (Hocking, 1997). Furthermore, only limited observations of the mean winds and tides have been made near $30^{\circ} \mathrm{N}$ latitudes past and present (e.g., Roper, 1975; Tsuda et al., 1987; Tsuda and Kato, 1988; Vincent et al., 1988; Nakamura et al., 1996; Hocke and Igarashi, 1998, 1999; Namboothiri et al., 1999, 2000; Igarashi et al., 2002; Hocking and Hocking, 2002). In such a background, wind observations of the meteor radar at Wuhan $\left(114.4^{\circ} \mathrm{E}\right.$, $30.6^{\circ} \mathrm{N}$ ) are particularly useful in understanding the tidal variations over China and at the transitional region from low to mid latitudes, and may be very helpful for the ongoing international efforts to achieve a better global climatology of the MLT region dynamics.

In this study, we report the seasonal behavior of the mean winds and diurnal and semidiurnal tides in the MLT region measured by the new installed meteor radar. The observed results are compared with the observations at similar lati-

Copy right(c) The Society of Geomagnetism and Earth, Planetary and Space Sciences (SGEPSS); The Seismological Society of Japan; The Volcanological Society of Japan; The Geodetic Society of Japan; The Japanese Society for Planetary Sciences; TERRAPUB. tudes and the latest model results. The meteor radar system and data analysis are described in Section 2. Then results for the mean winds and the diurnal and semidiurnal tides are presented in Section 3. A summary is made in Section 4.

\section{Wuhan Meteor Radar and Data Analysis}

An all-sky interferometric meteor wind radar has been operating at Wuhan $\left(114.4^{\circ} \mathrm{E}, 30.6^{\circ} \mathrm{N}\right)$, China, with a peak power of $7.5 \mathrm{~kW}$, a duty cycle of $10 \%$ at a frequency of 38.7 MHz and a height resolution of typically $<2 \mathrm{~km}$ since January 2002. And the pulse repetition frequency of the radar is $500 \mathrm{~Hz}$ in February-September 2002 and $1980 \mathrm{~Hz}$ from October 2002. The radar is a commercial VHF system manufactured by Atmospheric Radar Systems of Australia (ATRAD). The antenna array consists of crossed dipoles. A single aerial acts as the transmitter, and five separate aerials act as the receivers, which are configured as an interferometer. This system is almost identical to the Buckland Park meteor radar in Australia and the earlier SKiYMET system in Canada (Hocking et al., 2001; Holdsworth et al., 2004). Almost continuous observations have been carried out from February 2002 to February 2004, apart from a period of 10 days interruption in February 2002 and a big data gap of 56 days from February 26 to April 22 in 2003.

The mean daily meteor count recorded by Wuhan meteor radar is about 2500-3000, and almost all meteor echoes appear in the altitude region from $70 \mathrm{~km}$ to $110 \mathrm{~km}$ with the peak counts near $91 \mathrm{~km}$. The echo rates have a large diurnal variation, with the peak rates in the early morning hours and smaller rates in the evening hours. We only calculate the winds in the $80-100 \mathrm{~km}$ altitude region where the number of meteor echoes is enough.

To get the monthly and seasonal mean of the prevail- 
(a)

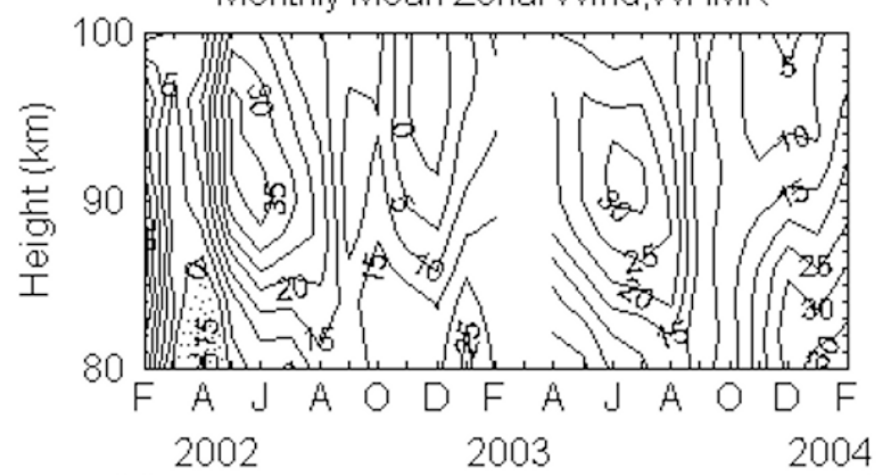

(c)

\section{Monthly Mean Zonal Wind,HWM93}

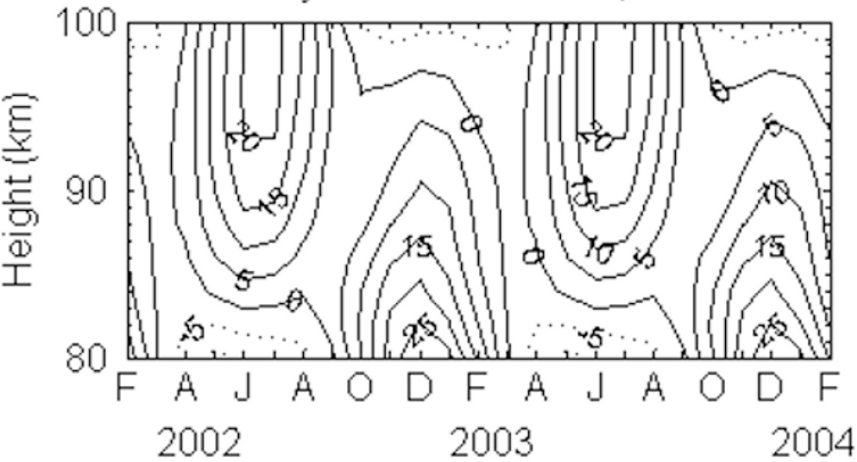

(b)

Monthly Mean Meridional Wind, WHMR

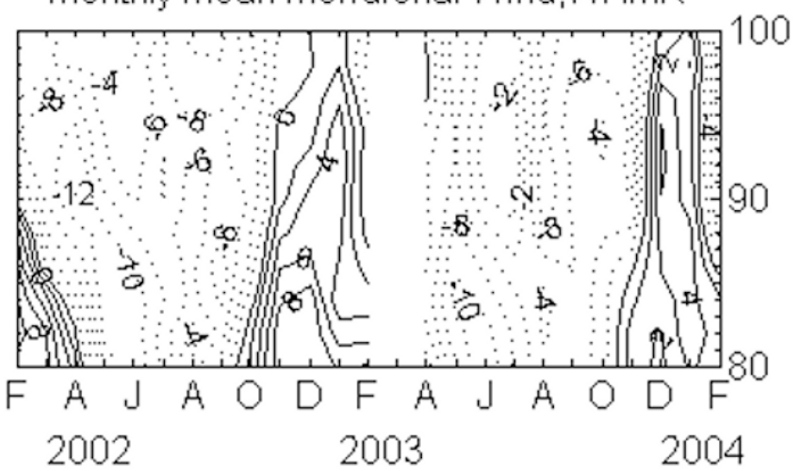

(d)

Monthly Mean Meridional Wind,HWM93

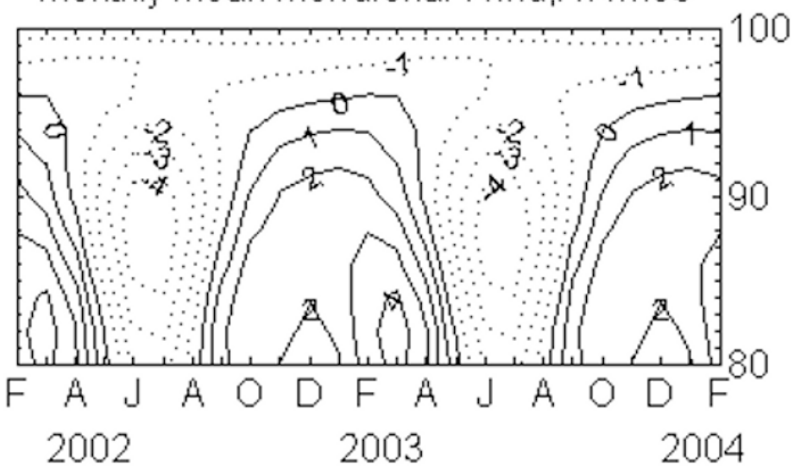

Fig. 1. (a) Monthly mean zonal and (b) meridional winds measured by Wuhan meteor radar from February 2002 to February 2004 (except in March 2003 for a data gap). (c) Monthly mean zonal and (d) meridional winds for $30^{\circ} \mathrm{N}$ from the HWM93. Eastward and northward flows are positive.

ing wind and tidal parameters, the data in each month or season were combined together as an equivalent day and accumulated into a time-altitude window of $2 \mathrm{~h} \times 3 \mathrm{~km}$ (Tsuda et al., 1987; Vincent et al., 1988; Reddi et al., 1993). The zonal and meridional winds in each window are inferred by applying a least-square fitting algorithm (Hocking et al., 2001). The window was advanced in steps of 1 hour and $2 \mathrm{~km}$, yielding 24-hour series of hourly averaged winds at each height window. Then a harmonic analysis was performed to retrieve the mean wind, the amplitudes and phases of the diurnal and semidiurnal tidal components. Because we have accumulated data over periods of 1 month or longer, there are sufficient meteors in each window, even in the evening hours.

In order to investigate the seasonal characteristics of the diurnal and semidiurnal tides in more detail, we also calculated tidal parameters at $90 \mathrm{~km}$ using a 9 days window with a shifting time step of 5 days.

\section{Results and Discussion \\ 3.1 Mean winds}

Figure 1(a) presents the monthly mean zonal winds measured over Wuhan from February 2002 to February 2004. The observed time mean zonal winds are dominated by eastward flows with strong vertical shears in solstices in the $80-90 \mathrm{~km}$ range. In summer months, the velocity of eastward wind changes from less than $10 \mathrm{~m} / \mathrm{s}$ at $80 \mathrm{~km}$ to more than $35 \mathrm{~m} / \mathrm{s}$ near $90 \mathrm{~km}$ in 2002, and more than $30 \mathrm{~m} / \mathrm{s}$ in 2003. In contrast, the winter zonal winds reach a maximum at the lowest height and are characterized by a negative ver- tical gradient. Below $85 \mathrm{~km}$, the winter eastward winds are found as large as $20-30 \mathrm{~m} / \mathrm{s}$. Above $90 \mathrm{~km}$, the winter zonal flows become very weak. The zonal wind shear near the summer and winter mesopause is believed to be caused by the momentum deposition of gravity waves (Lindzen, 1981; Dunkerton, 1982; Holton, 1982). The equinox winds appear as transitions between summer and winter flows, with a $10-15 \mathrm{~m} / \mathrm{s}$ eastward flow in September/October. There are weak eastward flows ( $<5 \mathrm{~m} / \mathrm{s})$ above $86 \mathrm{~km}$ in March/April and a stronger westward 'tongue' $(15-20 \mathrm{~m} / \mathrm{s})$ below $85 \mathrm{~km}$ in April 2002 which seems to be the top of the mesospheric spring-summer westward jet. At Wuhan, the reversal height of the summer mesosphere's westward jet is below $80 \mathrm{~km}$.

The similar strength of the summer eastward jet, observed for two consecutive years, suggests that the interannual variability is less evident in summer. But the winter zonal winds show higher variability from year to year, which can be caused by stratospheric planetary wave activities (Tsuda et al., 1987). Examining the zonal wind carefully, we can find that there is an abrupt spring transition and comparatively gradual fall transition in 2002. In contrast, there is a gradual spring transition and abrupt fall transition in 2003.

Figure 1(c) shows the monthly mean zonal wind of the HWM93 model (Hedin et al., 1996). A comparison of the observed zonal winds and the HWM93 model winds reveals similar wind patterns and also some significant differences. The model shows a much weaker summer eastward wind compared to that observed by the radar. The maximum summer eastward wind is a little more than $20 \mathrm{~m} / \mathrm{s}$ in the 
(a)

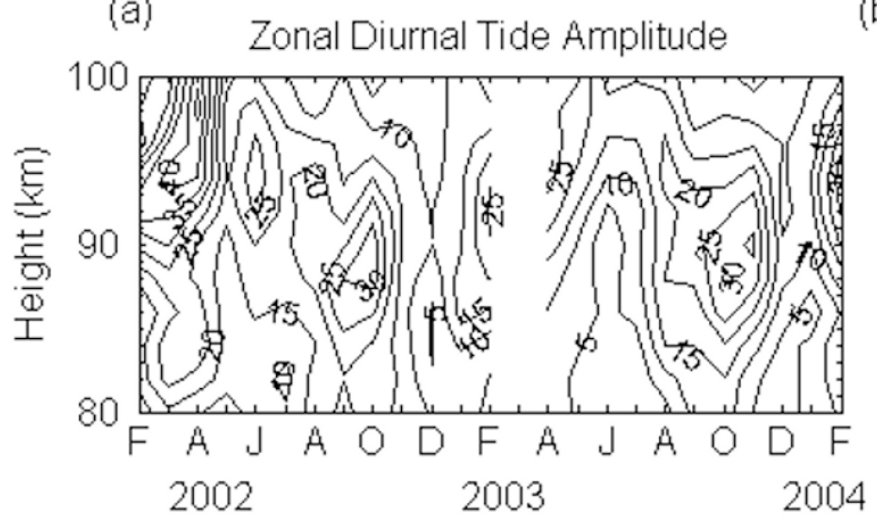

(c) 2002

(b)

\section{Meridional Diurnal Tide Amplitude}

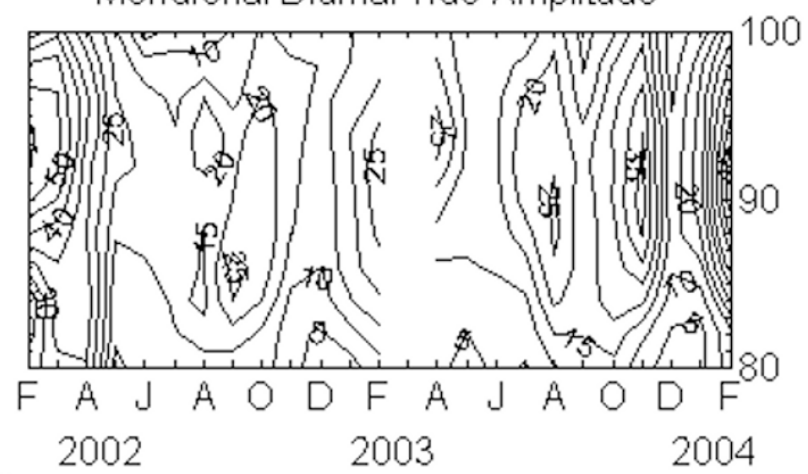

(d)

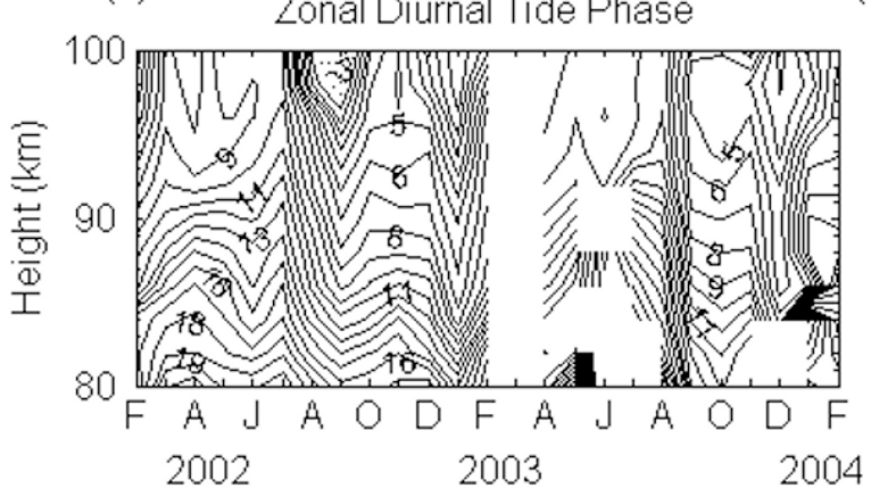

Meridional Diurnal Tide Phase

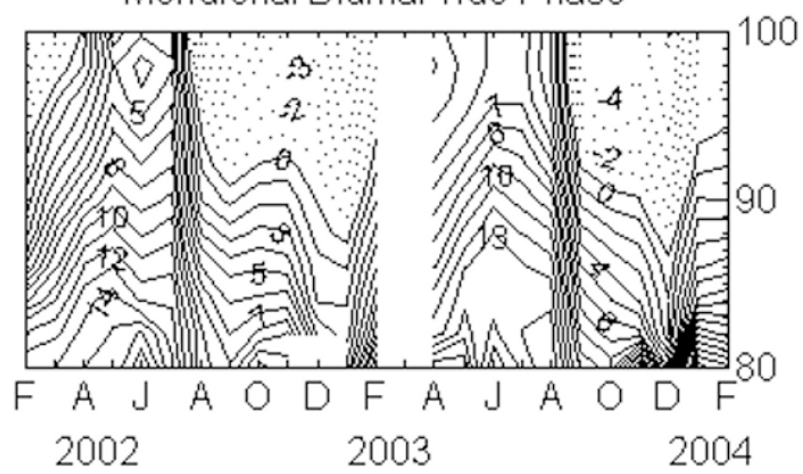

Fig. 2. (a) Monthly mean amplitude of the zonal component and (b) monthly mean amplitude of the meridional component of the diurnal tide. (c) Monthly mean phase of the zonal component and (d) monthly mean phase of the meridional component of the diurnal tide (in local time, LT=UT+8). The phases haven't been given when the amplitudes less than $2 \mathrm{~m} / \mathrm{s}$.

model, and is $30-35 \mathrm{~m} / \mathrm{s}$ measured by the radar. The transition height of the summer zonal winds is located at about $84 \mathrm{~km}$ for the HWM93 model but is below $80 \mathrm{~km}$ in the observations. Furthermore, the observed strong westward flow below $86 \mathrm{~km}$ in March/April 2002 seems to be much weaker in the model results.

Figure 1(b) illustrates the monthly mean meridional wind measured by the radar. For the meridional component, the data reveals a poleward flow in winter and an equatorward flow in other seasons, and the meridional wind is usually smaller than $12 \mathrm{~m} / \mathrm{s}$. The strongest equatorward flow (slightly more than $10 \mathrm{~m} / \mathrm{s}$ ) appears in April-June of 2002 and in May-June of 2003. In 2002, these equatorward peaks firstly emerge in April at 90-94 km and shift downward with time, at last descend to heights near $80 \mathrm{~km}$ in June. In May-June of 2003, the maximum equatorward wind appears only below $85 \mathrm{~km}$. In the first two winters, the meridional flow shows a clear negative height gradient with a velocity changing from $8-9 \mathrm{~m} / \mathrm{s}$ poleward near $80 \mathrm{~km}$ to weak equatorward near $100 \mathrm{~km}$. In the winter of 2004, the poleward wind is weaker than that in the previous two years at lower heights.

The monthly mean meridional winds predicted by the HWM93 for $30^{\circ} \mathrm{N}$ are presented in Fig. 1(d). The general pattern of the observations and the HWM93 wind is similar, but there are also significant differences. Firstly, the model has a very weak meridional wind with magnitudes less than $5 \mathrm{~m} / \mathrm{s}$ in the whole year, which does not reach half of the observed values. Furthermore, the measured meridional flow does not have the significant poleward region, which is evident in the model.

Comparing the meteor radar mean winds at Wuhan with the Yamagawa $\left(141.7^{\circ} \mathrm{E}, 31.2^{\circ} \mathrm{N}\right) \mathrm{MF}$ radar measurements (Namboothiri et al., 2000), we can see that there is a reasonable agreement. At both places the zonal winds are of similar strengths and the circulation features have considerable resemblance. The meridional winds are also consistent in their intensities of the equatorward/poleward cell. But below $90 \mathrm{~km}$, the meridional flows at Yamagawa are more northward than those at Wuhan. The southward flows at Yamagawa extend to lower heights $(<90 \mathrm{~km})$ only during summer months. This discrepancy probably reflects instrument biases between MF and meteor radars.

The MU radar at Shigaraki, Japan $\left(35^{\circ} \mathrm{N}, 136^{\circ} \mathrm{E}\right)$ also provided good observations of mean winds at $60-90 \mathrm{~km}$ altitudes (Nakamura et al., 1996; Namboothiri et al., 1999). We can compare those results with Wuhan meteor radar observations in 80-90 km heights range. Both similar and obvious differences are found between the two measurements. In the MU zonal wind, the summer westward cell appeared to close in the $82-90 \mathrm{~km}$ height region, which is clearly higher than the Wuhan results. It is noted that the Kyoto meteor observations nearby gave a reverse height of summer zonal wind similar to Wuhan. So it maybe indicates an instrument biases. The comparison of the meridional wind is generally not satisfactory. The MU radar gave a more northward and stronger meridional wind. The northward flow started from August for the MU radar, but only 


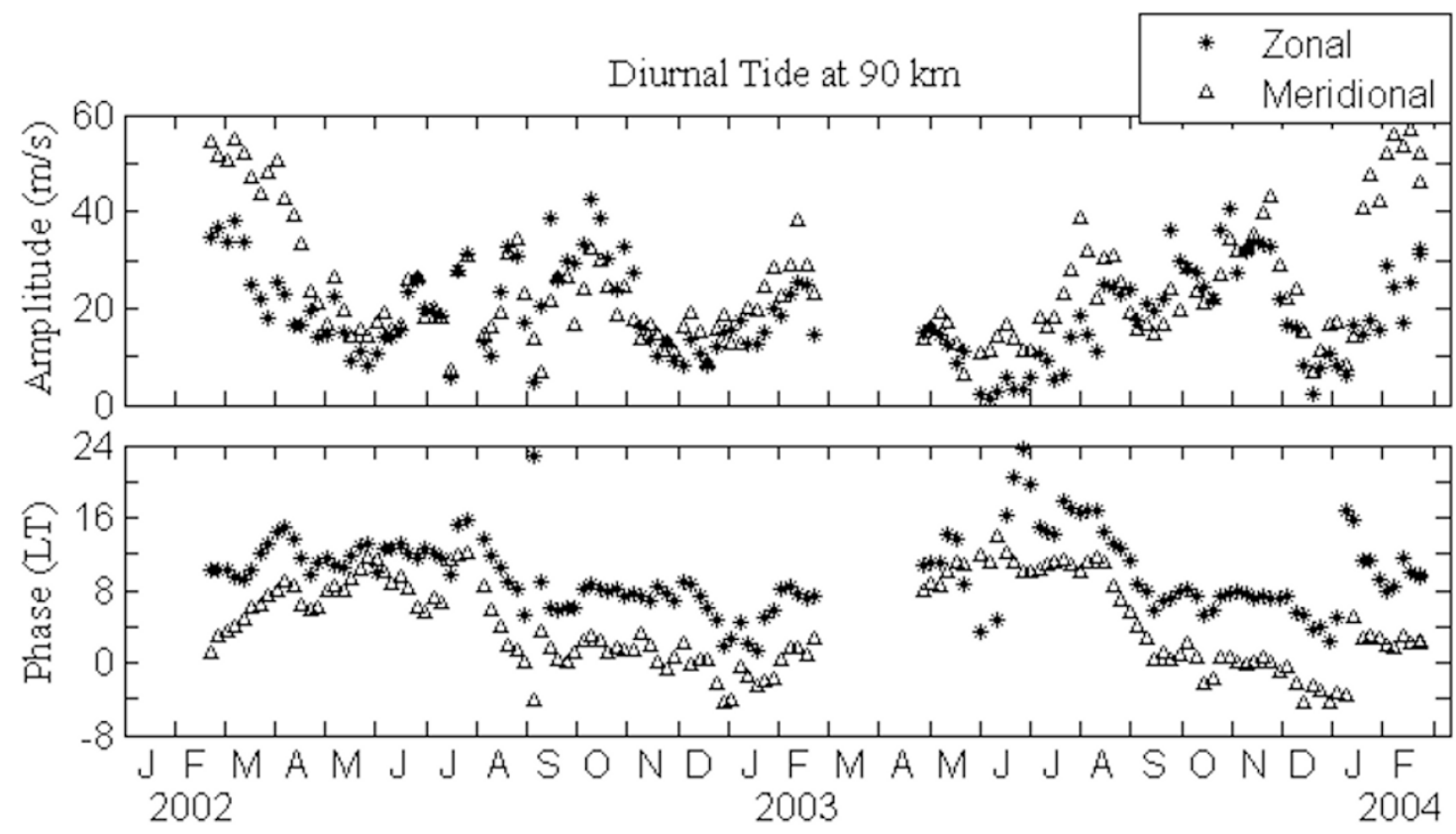

Fig. 3. The diurnal tidal amplitude and phase observed at Wuhan for the height of $90 \mathrm{~km}$.

appeared from October to April at Wuhan. The southward flow appeared in February are also not observed at Wuhan. Especially for the very strong northward (reached $30 \mathrm{~m} / \mathrm{s}$ ) winds near $90 \mathrm{~km}$ in April and near $80 \mathrm{~km}$ in November, which are not observed by Wuhan meteor radar. These differences may partly result from the data analysis. First, The MU mean winds were obtained by a simple averaging of the 12 hours wind velocity during daytime (Nakamura et al., 1996; Namboothiri et al., 1999), which should be biased by the strong daily fluctuation at mid-low latitudes. Second, the monthly mean winds of MU radar is only derived from 5 days data per month could also bias the comparison.

Tsuda et al. (1987) presented measurements of mean winds made by the Kyoto $\left(35^{\circ} \mathrm{N}, 136^{\circ} \mathrm{E}\right)$ meteor radar in the period 1983-1985. A good consistent, involved the summer eastward wind amplitudes, the summer reverse altitude and the season variation manner, are found in the zonal component between winds measured over Kyoto and Wuhan. But the meridional mean winds measured over Kyoto seem to be more irregular than those over Wuhan. At Wuhan, the northward winds generally appear in winter. However over Kyoto, besides the weakly northward winds in winter, relatively large northward mean winds were detected in May, June 1983 and June 1984 at altitudes above $97 \mathrm{~km}$. The northward is also recognized below $85 \mathrm{~km}$ in March, April, September and October at Kyoto.

\subsection{The diurnal tide}

Figure 2(a) and 2(b) present the monthly mean amplitudes of the diurnal tide (DT) for the zonal and meridional components, respectively. The amplitudes of the two components are very similar in most months except that the meridional amplitude is obviously larger than the zonal one in spring. A strong seasonal dependence can be seen in the DT amplitudes. The tidal amplitudes attain the maximum values near spring equinox. The largest DT amplitudes of zonal component are observed (>40 m/s) during March-
April, while the meridional maximum amplitudes are found ( $>50 \mathrm{~m} / \mathrm{s}$ ) during February-March. At Wuhan, the diurnal tides reach a secondary maximum near autumn equinox, and are usually weaker in solstice months. Examining the diurnal tides structure, we can find that the peak height of the DT amplitude is higher in spring than in fall. It indicates the diurnal tide in spring can propagate further into the mesosphere before breaking in the background mesosphere atmosphere.

Equinoctial maxima of the DT amplitude were also observed at Adelaide (Vincent et al., 1998) and by the UARS spacecraft (Burrage et al., 1995; McLandress et al., 1996). Mayr et al. (1998) attributed the equinoctial maxima to the gravity wave absorption and filtering caused by the mean zonal circulation. Vincent et al. (1988) suggested that the reduced dissipation in equinoxes results in these maxima.

Observations from Adelaide (Vincent et al., 1998) revealed a biennial variation in the diurnal tidal amplitude in March-April. Unfortunately we can't check the interannual variation in March-April at Wuhan due to the data gap. But from measurements in February we found a strong interannual variability. The DT amplitudes in February 2002 and 2004 exceed those in February 2003 by a factor of 1.5 for the zonal component and a factor of 2 for the meridional component. Interannual variability is also found in November. The amplitudes in November for both DT components are nearly the minimum in the year 2002, but they are the maximum amplitudes in 2003.

The phases of the diurnal tide are shown in Fig. 2(c) and 2(d). The tidal phase values correspond to the hour in local time (at Wuhan LT $=\mathrm{UT}+8$ ) of the maximum eastward (for zonal) and maximum northward (for meridional) winds. It should be noted that the phases are not presented here when the tidal amplitudes are smaller than $2 \mathrm{~m} / \mathrm{s}$, so as to avoid inaccurate estimation (for example, the zonal phase below $92 \mathrm{~km}$ in June 2003). The diurnal tidal phases of both wind 
(a)

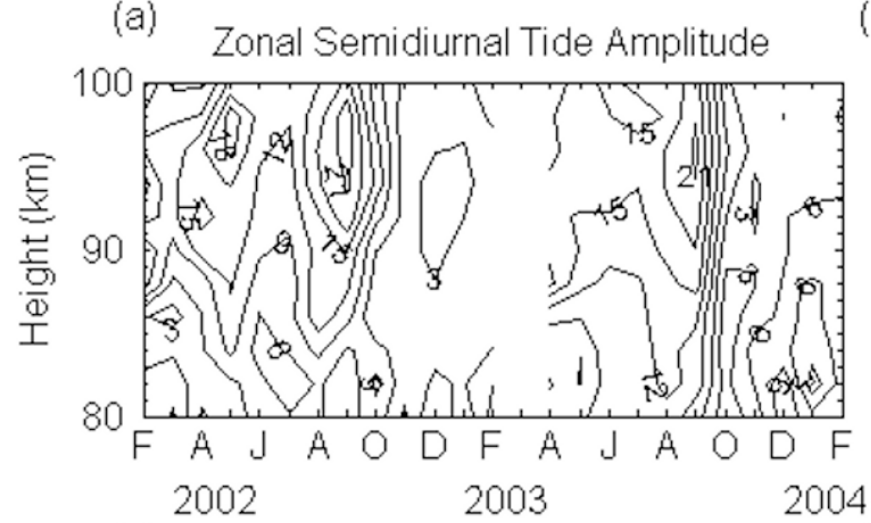

(c)

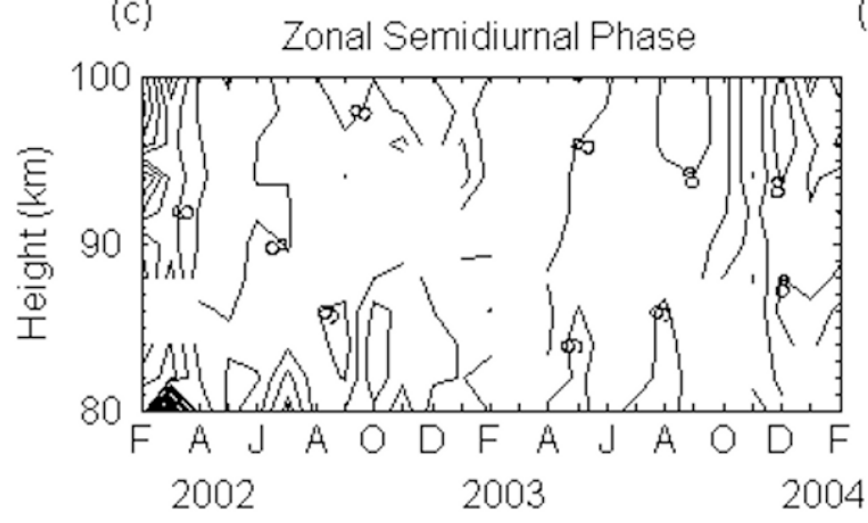

(b) Meridional Semidiurnal Amplitude

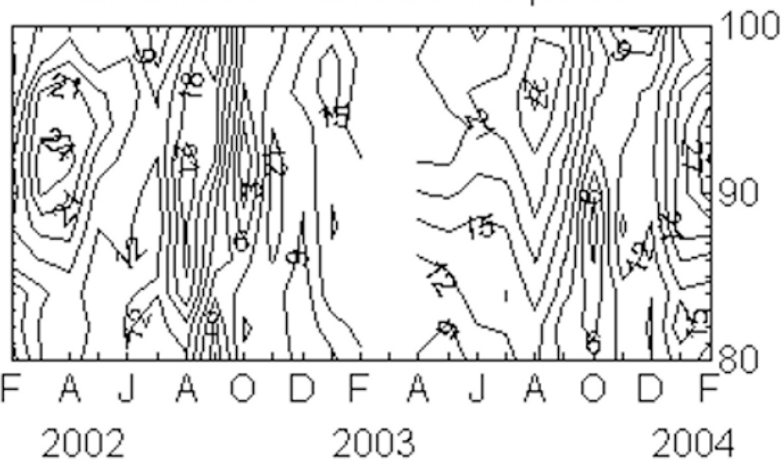

(d)

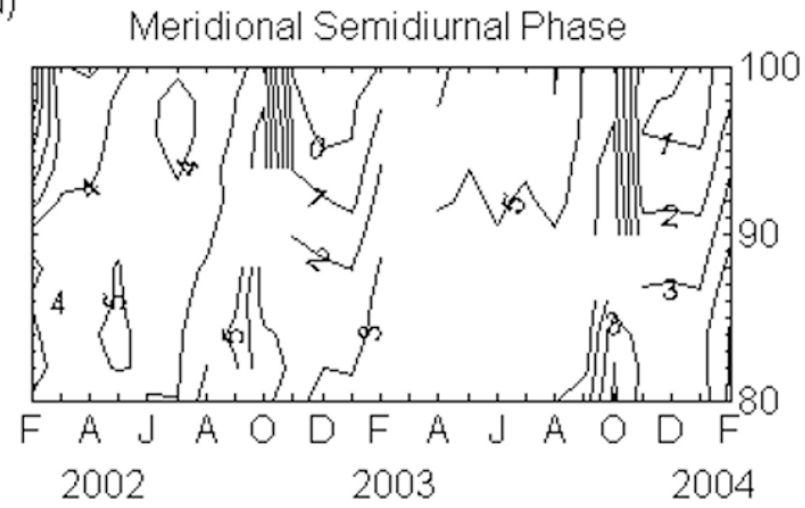

Fig. 4. Same as Fig. 2. but for the semidiurnal tide.

components show clear downward phase propagation. The phase gradient of the DT presents a vertical wavelength of $30-50 \mathrm{~km}$, indicating a main diurnal tide $S(1,1)$ mode. A clear phase annual variation is found in both components especially in the meridional DT with fast phase transitions just before equinoxes (in February and August). At each height, the DT phases in September-January are around 4-5 $\mathrm{h}$ earlier than those in March-July for the zonal component, and for the meridional component, the advance of phase reaches 8-9 h.

Figure 3 gives the DT parameters at $90 \mathrm{~km}$ over Wuhan, which was calculated using a 9-day sliding window with a time step of 5 days. From Fig. 3, we can see that the diurnal tides usually enhance at equinoxes and weaken at solstices. A clear phase bimodal structure can be found at $90 \mathrm{~km}$ where the phase of zonal component is around 78 LT from September to December and around 12-13 LT from March to July. The DT phase of the meridional component usually precedes the zonal component $2-4 \mathrm{~h}$ in summer and 6-7 h in winter, suggesting a right rotating circular polarization in winter and a linearly polarized tendency in summer. The strong quasi-periodic variations with periods about 20-40 days are found in the DT phases, which suggests interferences among several waves.

A special comparison is made with measurements at Yamagawa $\left(141.7^{\circ} \mathrm{E}, 31.2^{\circ} \mathrm{N}\right)$, which is located at similar latitude to Wuhan. The long-term MF radar observations at Yamagawa show strong DT amplitudes in spring/fall/winter, with a maximum in winter (Hocke and Igarashi, 1999; Igarashi et al., 2002). But in our observations the DT is strongest in spring and weakest in winter. At Yamagawa, the DT meridional component is generally smaller than the zonal component, which is contrary to our observations. Furthermore, the extra strong DT amplitudes (40-55 m/s) observed at Wuhan in February-April are not seen at Yamagawa. The phase values show good agreement at both locations. And the same phase bimodal structure is also depicted at Yamagawa (Hocke and Igarashi, 1999; Igarashi et al., 2002).

Observations by the Kyoto meteor radar (Vincent et al., 1988) generally revealed much smaller DT amplitudes, compared to Wuhan results. However, Kyoto observations also gave maximum values at spring months. And at Kyoto, the DT amplitudes also showed evidence of interannual variability in March-April. The vertical wavelengths inferred from the phase gradients are also similar at both locations. Recently, Hocking and Hocking (2002) have investigated the temperature tides with Albuquerque $\left(35^{\circ} \mathrm{N}\right.$, New Mexico) meteor radar. The wind tidal amplitudes and phases in four months (December/January/February/March) are also presented in Fig. 2 and Fig. 3 of their paper. The similar DT amplitudes to our measurements and the spring equinox amplitude maximum (near $40 \mathrm{~m} / \mathrm{s}$ in March) are also found at Albuquerque.

\subsection{The semidiurnal tide}

Figure 4(a) and 4(b) present contours of the monthly mean amplitudes of the semidiurnal tide (SDT) for the zonal and meridional components, respectively. At Wuhan, the SDT is markedly weaker than the DT, which is consistent with the finding that the DT is strong at low latitudes and the SDT dominant poleward above $\sim 40^{\circ}$ (Burrage et al., 1995). The zonal SDT amplitudes $(5-20 \mathrm{~m} / \mathrm{s})$ are generally 

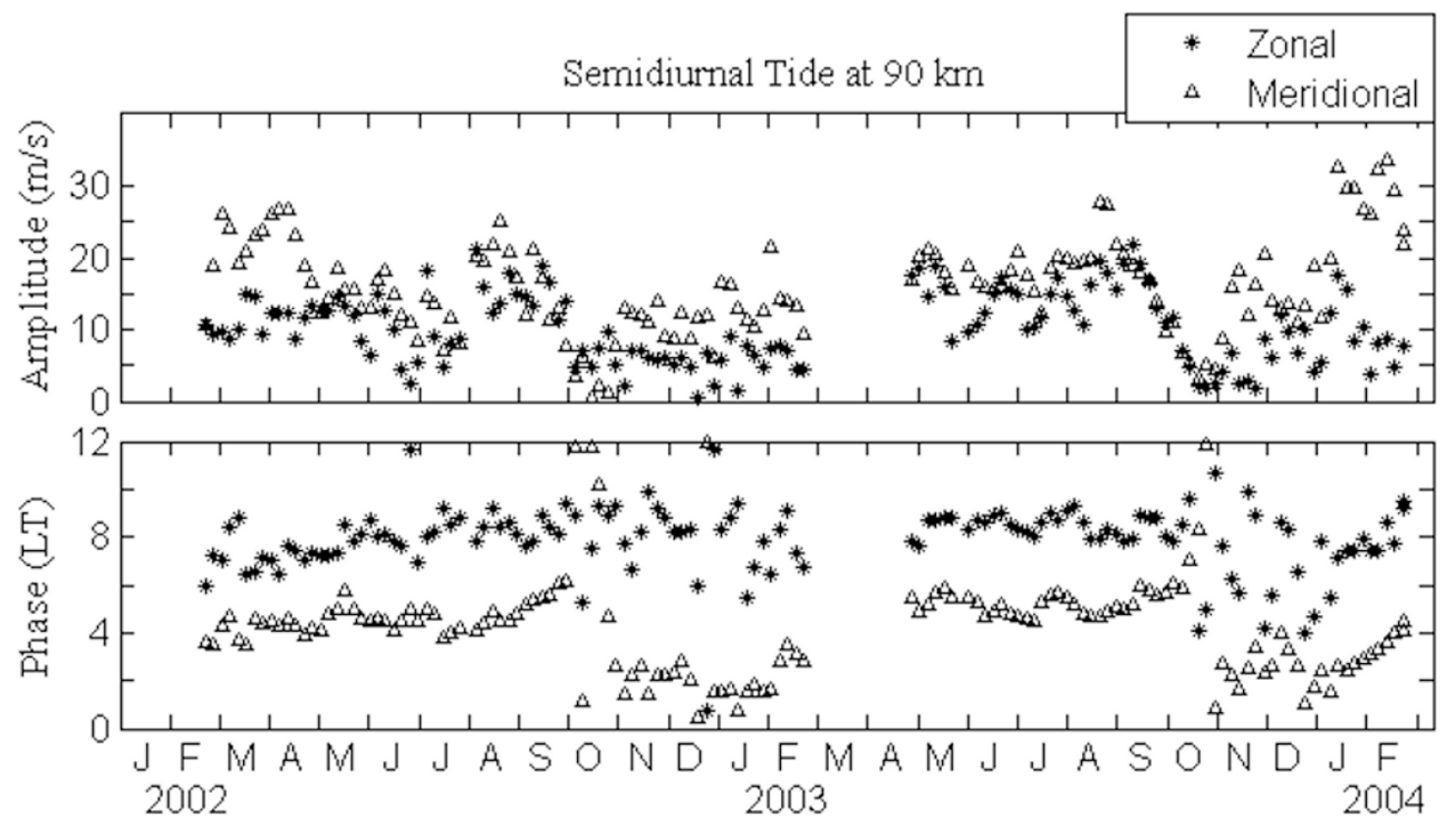

Fig. 5. Same as Fig. 4. but for the semidiurnal tide.

smaller than the meridional amplitudes $(10-30 \mathrm{~m} / \mathrm{s})$. Both the zonal and meridional SDT amplitudes reach their peaks near equinoxes (March-May, August-September). In summer solstice months (June-July), especially in 2003, the SDT also attains considerable amplitude. From the late autumn and into winter months, the SDT amplitudes become the smallest, falling to as low as $<8 \mathrm{~m} / \mathrm{s}$ in the zonal component and $<15 \mathrm{~m} / \mathrm{s}$ in the meridional component. It is interesting to note that the largest amplitudes (reaching 20-30 $\mathrm{m} / \mathrm{s}$ above $86 \mathrm{~km}$ ) are observed in February of 2004 for the meridional SDT, which are 2 times larger than observations in February of 2002 and 2003, and are 3-4 times larger than the zonal ones at the same term.

The SDT phases are presented in Fig. 4(c) and 4(d). The profiles of the SDT phases mostly show downward phase propagation. The vertical wavelength of the zonal component is usually much longer $(>150 \mathrm{~km})$. For the meridional component, the vertical wavelength appears to be smaller in winter $(\sim 50 \mathrm{~km})$, and seems to be longer than $150 \mathrm{~km}$ in other seasons. This suggests the higher order modes $(\mathrm{S}(2,4)$ or $\mathrm{S}(2,5))$ in winter and the fundamental mode in other seasons, according to the classical tidal theory (Kato, 1980; Forbes, 1982). The average phases of meridional SDT are around 4-5 LT (except in winter) and those of zonal component are around 7-8 LT. As a result, the phase of the meridional component leads the zonal component by around $3 \mathrm{~h}$. A clear phase annual variation is found in the meridional SDT with a phase earlier 3-5 $\mathrm{h}$ in winter than that in other seasons. It should be noted that this phase annual variation corresponds very well to the transition of the vertical wavelength (or the transition of the tide modes). For the zonal SDT phase, the annual variation is faint.

Figure 5 shows the variation of amplitudes and phases of the SDT at $90 \mathrm{~km}$. As depicted in Fig. 5, the zonal amplitude is generally smaller than the meridional component. Both components reach the maximum in March and $\mathrm{Au}-$ gust, and in October they decrease to the minimum. Note that the decrease of amplitude in October coincides with a period of rapid phase advance in the meridional component, suggesting interference between the fundamental mode and higher modes during this period. An obvious phase bimodal structure exists in the meridional SDT with phase abrupt transitions in the beginning of October and in the middle of February. The winter state of the semidiurnal phases (October-January) is obviously shorter than the summer state. For the zonal component, the phase annual variation is not clearly seen. The phases of the eastward and northward components usually show quadrature relations, but they are 180 degrees out of phase in winter, indicating a linearly polarization in winter but a circular polarization in other seasons.

A comparison of our observations with the MF observations (Hocke and Igarashi, 1999; Igarashi et al., 2002) shows similar SDT amplitudes and seasonal variations at both stations. The phase characteristics is also similar for the two locations, except that the phase bimodal structure in the zonal component is not clear at Wuhan. There are also some consistencies in semidiurnal tidal structure between our site and Kyoto (Tsuda and Kato, 1988; Vincent et al., 1988), such as the similar semidiurnal tidal amplitudes and autumn equinox amplitude maximum. But the spring equinox maximum is not clearly seen at Kyoto.

\subsection{Comparison of tides with the GSWMO0 model}

In this section the seasonal averaged tidal parameters observed over Wuhan are compared with the predictions of the Global Scale Wave Model 2000 (GSWM00) (Hagan et al., 1999). In our analysis, we have defined March-May as spring (a big data gap occurs in 2003 spring), June-August as summer, September-November as fall and DecemberFebruary as winter.

The seasonal mean amplitudes and phases of the diurnal tide for the zonal component are presented in Fig. 6, while 

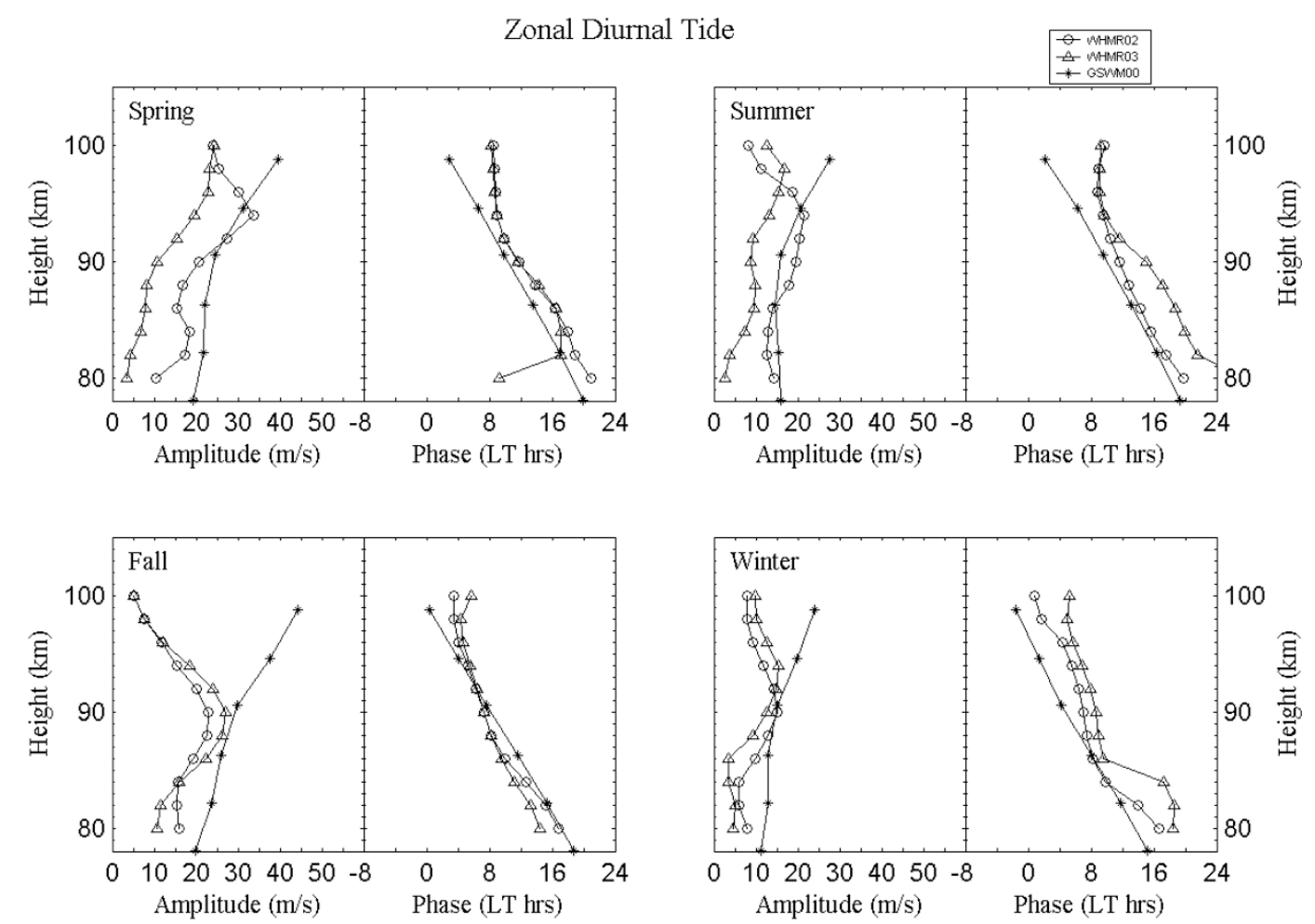

Fig. 6. Seasonal means of the amplitude and phase of the zonal components of the diurnal tide during spring, summer, fall and winter for the years 2002 and 2003. The GSWM00 values are also given for comparison.
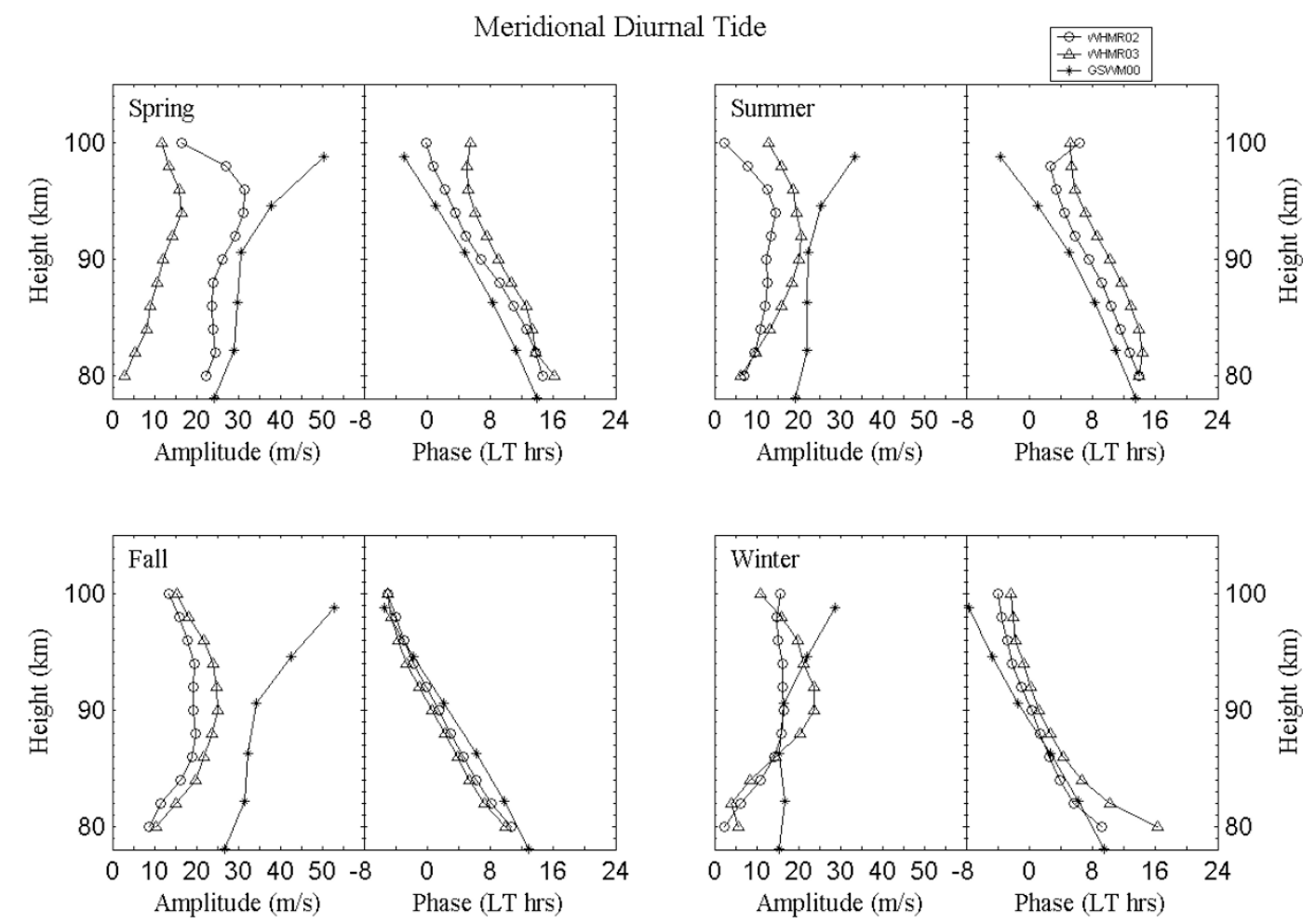

Fig. 7. Same as Fig. 6. but for the meridional component.

the equivalent results for the meridional component are presented in Fig. 7. The observed DT amplitudes are generally smaller than those of the GSWM. The greatest difference in amplitude between the observations and the GSWM occurs in fall above $90 \mathrm{~km}$. At $98 \mathrm{~km}$, the observed zonal ampli- tudes in 2002 and 2003 are about $5 \mathrm{~m} / \mathrm{s}$, whereas the model amplitude reaches $44 \mathrm{~m} / \mathrm{s}$, and for the meridional component, the observed value is about $15 \mathrm{~m} / \mathrm{s}$ compared to 53 $\mathrm{m} / \mathrm{s}$ in the model. Both the observations and the GSWM exhibit peaks of the DT amplitude near equinoxes (apart from 

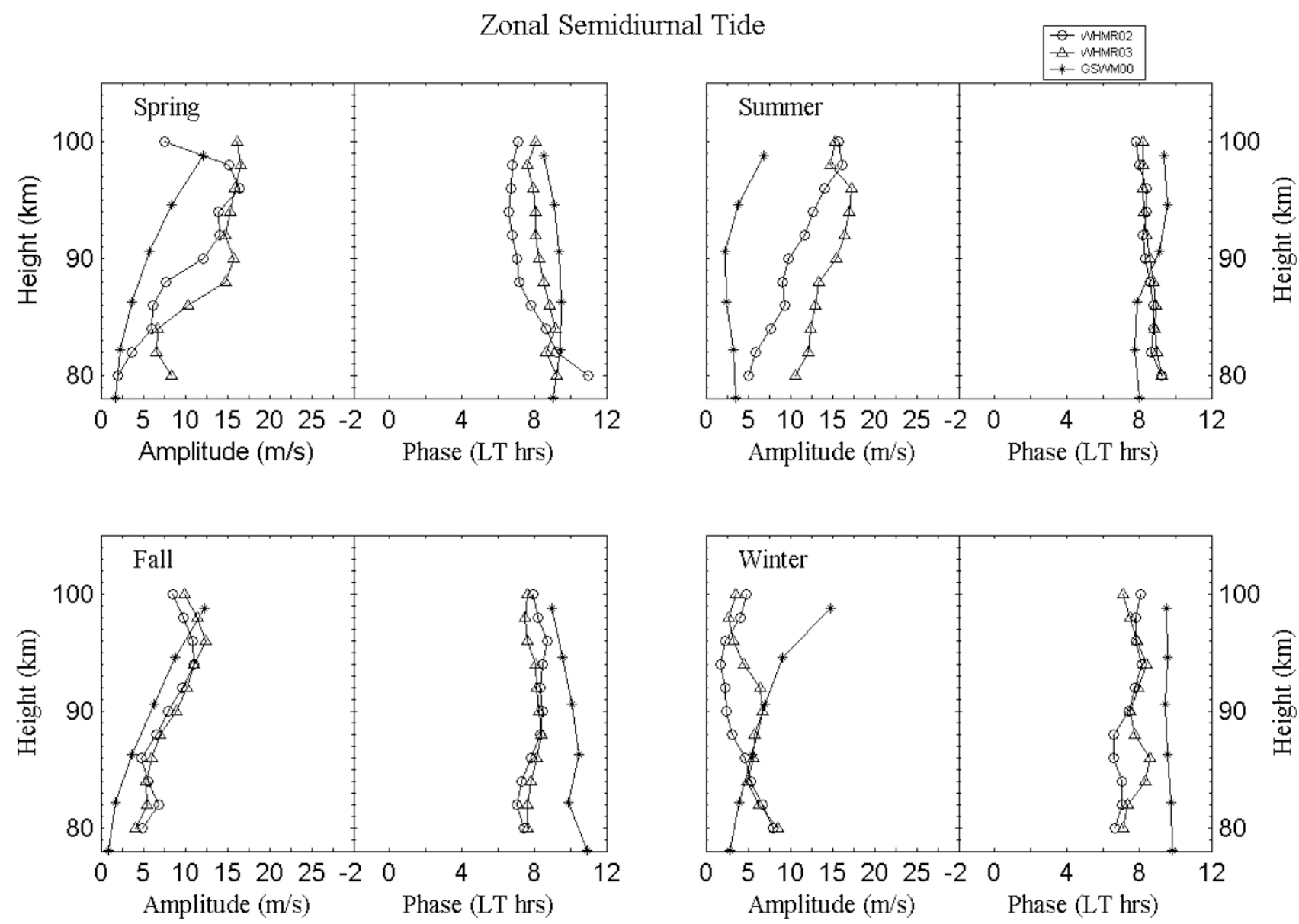

Fig. 8. Same as Fig. 6. but for the semidiurnal tide.

the observations in spring 2003 when a big data gap exists). But the observations reach the maximum in spring equinox, and in the model the largest amplitudes appear in autumn equinox. In our observations, the maximum DT amplitudes appear at $94-98 \mathrm{~km}$ in spring and summer, at $\sim 90 \mathrm{~km}$ in fall and winter. The GSWM results have almost constant amplitudes below $90 \mathrm{~km}$, above which the amplitudes increase monochromatically.

Comparison of the observed diurnal tidal phases with the GSWM model outputs show good agreement at almost all heights, and the observed phases display good stability from year to year. The best agreement of the observed phases with the model appears in fall, when the phase differences are only $1-2 \mathrm{~h}$ for both the zonal and meridional DT components. The greatest differences are found in summer 2003 for both DT components with the observed phases lagging those of the GSWM about 4-6 h. But it is still a good agreement according to the criterion proposed by Manson et al. (1999), who considered an agreement in phase angle between the GSWM and the observations less than $90^{\circ}$ (corresponding $6 \mathrm{~h}$ for the diurnal tide) to be good. The phase gradients of the GSWM are slightly weaker than the observations, and the corresponding vertical wavelengths are $\sim 29 \mathrm{~km}$, shorter than the observed 30-50 km. Furthermore, there is little phase change with height observed above 95 $\mathrm{km}$ in some seasons, indicating an evanescent characteristic, which are not predicted by the GSWM.
A similar analysis for the seasonal mean amplitudes and phases of the semidiurnal tide is presented in Fig. 8 and 9. The comparison of the measured SDT parameters and the GSWM is not satisfactory. As can be seen, the observed SDT amplitudes are generally larger than the GSWM model results except in fall/winter for the zonal amplitude and in fall for the meridional component. In fall, the zonal component shows a good resemblance to the model, and the meridional SDT amplitudes are less than the model above $90 \mathrm{~km}$ for 2002. In winter, the observed SDT amplitudes of the zonal component are also smaller than those in the GSWM. Again the GSWM reaches the maximum above $100 \mathrm{~km}$, but the measured maxima usually appear in the observed range.

The observed SDT phases are generally earlier than the results of the GSWM except below $90 \mathrm{~km}$ in summer for both components. The phase differences between the observations and the model are generally less than $90^{\circ}$ (corresponding $3 \mathrm{~h}$ for the semidiurnal tide), but some exceptions lie in fall and winter for the meridional wind. In most instances, both the observations and the GSWM show a very large vertical wavelength. But the meridional phase of the GSWM in fall and the meridional phase of the observations in winter give short vertical wavelengths $(\sim 40 \mathrm{~km}$ and $\sim 50$ $\mathrm{km})$, which don't appear simultaneously in their counterpoints. 

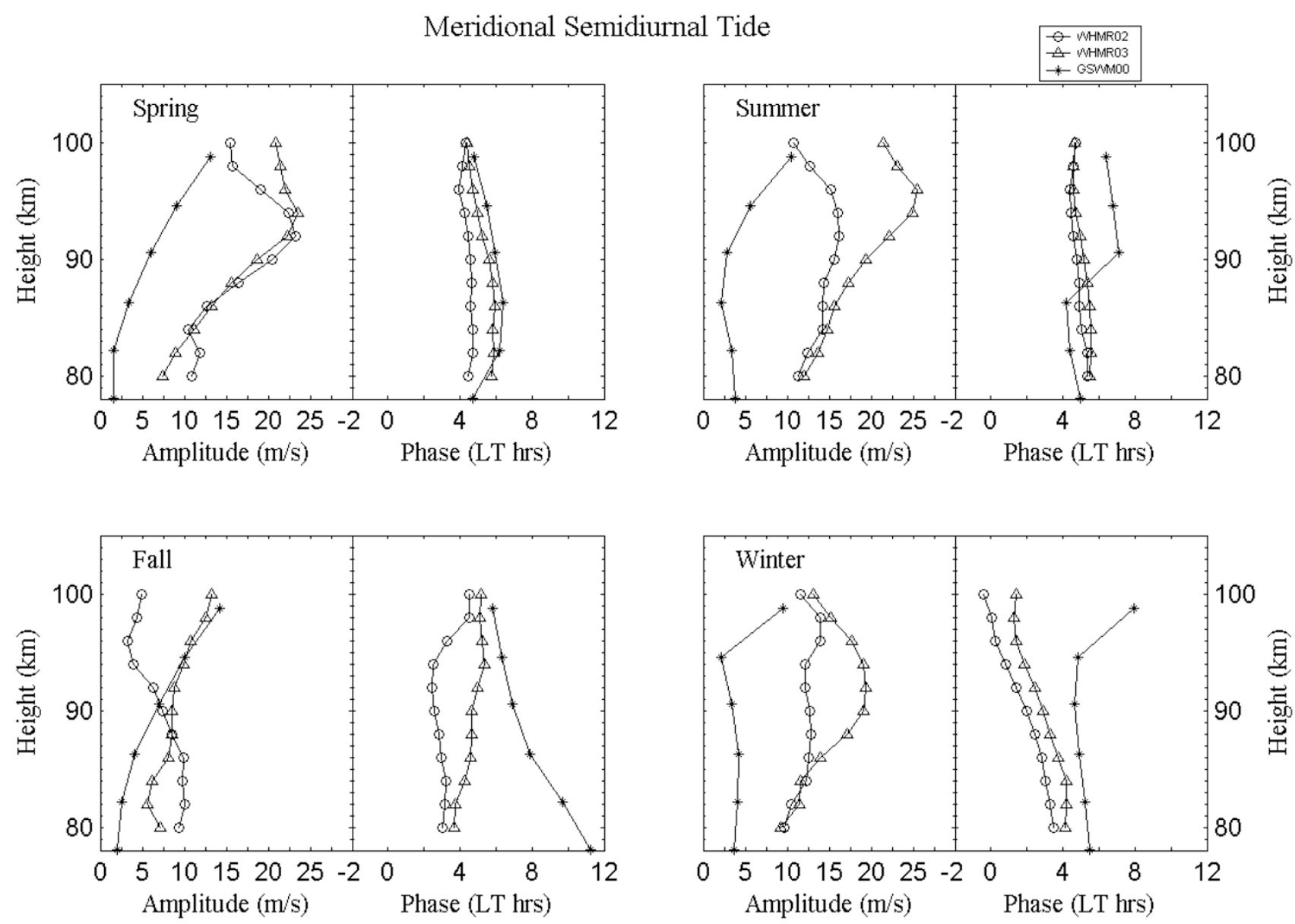

Fig. 9. Same as Fig. 6. but for the meridional component of the semidiurnal tide.

\section{Summary}

The first 25 months of observations by a new meteor radar at Wuhan $\left(114.4^{\circ} \mathrm{E}, 30.6^{\circ} \mathrm{N}\right)$ are used to investigate the mean wind and tidal characteristics in the MLT range at heights between 80 and $100 \mathrm{~km}$. The time mean zonal winds are dominant eastward with westward flow occasionally appearing in March-April at the lower meteor heights. A strong zonal flow shear is found near the summer mesopause with strong eastward winds of $30-35 \mathrm{~m} / \mathrm{s}$ at the heights of 90-94 km. The time mean meridional winds are poleward in winter and equatorward in other seasons. Comparisons with the HWM93 model reveals good wind patterns, but the strength of the summer eastward wind and especially the strength of the meridional wind, are obviously weaker in the HWM93 than the observations.

The diurnal tides are dominant in the two tidal components. Both the diurnal and semidiurnal tides have equinoctial maxima and solstitial minima. The diurnal tidal amplitude in March/April 2002 exceeds $40 \mathrm{~m} / \mathrm{s}$ and $50 \mathrm{~m} / \mathrm{s}$ for the zonal and meridional components, respectively. A clear bimodal structure is found in the phases of the diurnal tide and the meridional semidiurnal tide, with a phase advancing in winter than in summer. In most conditions, a right rotating circular polarization is found for both diurnal and semidiurnal tides.

Compared the observed tides with the GSWM model results, the observed diurnal amplitudes are generally smaller than the model, and the semidiurnal amplitudes are usually larger than the results of the GSWM. The results of GSWM demonstrate that the tidal amplitudes of both DT and SDT increase monochromatically with increasing height. However, the observed tidal amplitudes usually decrease at higher heights. The observed phases are in good agreement with the GSWM phases, especially for the diurnal tide.

Acknowledgments. We thank Prof. A. Hedin providing the program of HWM93 and Dr. Hagan providing the tabulations of the GSWM00. This research was supported by National Natural Science Foundation of China (40134020), the KIP Pilot Project (K2CX3-SW-144) and Important Basis Research Project of China (G2000078407).

\section{References}

Burrage, M. D., M. E. Hagan, W. R. Skinner, D. L. Wu, and P. B. Hays, Long-term variability in the solar diurnal tide observed by HRDI and simulated by the GSWM, Geophys. Res. Lett., 22, 2641-2644, 1995.

Dunkerton, T. J., Theory of the mesopause oscillation, J. Atmos. Sci., 39, 2681-2690, 1982.

Forbes, J. M., Atmospheric tides 2. The solar and lunar semidiurnal components, J. Geophys. Res., 87, 5241-5252, 1982.

Hagan, M. E., D. M. Burrage, J. M. Forbes, J. Hackney, W. J. Randel, and X. Zhang, GSWM-98: Results for migrating solar tides, J. Geophys. Res., 104, 6813-6828, 1999.

Hedin, A. E., E. L. Fleming, A. H. Manson, F. J. Schmidlin, S. K. Avery, R. R. Clark, S. J. Franke, G. J. Fraser, T. Tsuda, F. Vial, and R. A. Vincent, Empirical wind models for the upper, middle and lower atmosphere, $J$. Atmos. Terr. Phys., 58, 1421-1447, 1996. 
Hocke, K. and K. Igarashi, Mean winds in the mesopause region observed by MF radars at $31^{\circ}$ and $45^{\circ} \mathrm{N}$, J. Atmos. Solar-Terr. Phys., 60, 10811087, 1998.

Hocke, K. and K. Igarashi, Diurnal and semidiurnal tide in the upper middle atmosphere during the first year of simultaneous MF radar observation in northern and southern Japan $\left(45^{\circ} \mathrm{N}\right.$ and $\left.31^{\circ} \mathrm{N}\right)$, Ann. Geophysicae, 17, 405-414, 1999.

Hocking, W. K., Recent advances in radar instrumentation and techniques for studies of the mesosphere, stratosphere, and troposphere, Radio Sci., 32, 2241-2270, 1997.

Hocking, W. K. and A. Hocking, Temperature tides determined with meteor radar, Ann. Geophysicae, 20, 1447-1467, 2002.

Hocking, W. K., B. Fuller, and B. Vandepeer, Real-time determination of meteor related parameters utilizing modern digital technology, J. Atmos. Solar-Terr. Phys., 63, 155-169, 2001.

Holdsworth, D. A., I. M. Reid, and M. A. Cervera, Buckland Park all-sky interferometric meteor radar, Radio Sci., 39, RS5009, doi:10.1029/2003RS003014, 2004

Holton, J. R., The role of gravity wave induced drag and diffusion in the momentum budget of the mesosphere, J. Atmos. Sci., 39, 791-799, 1982.

Igarashi, K., S. P. Namboothiri, and P. Kishore, Tidal structure and variability in the mesosphere and lower thermosphere over Yamagawa and Wakkanai, J. Atmos. Solar-Terr. Phys., 64, 1037-1053, 2002.

Kato, S., Dynamics of the Upper Atmosphere, D. Reidel, Hingham, Mass., 1980.

Lindzen, R. S., Turbulence and stress owing to gravity wave and tidal breakdown, J. Geophys. Res., 86, 9707-9714, 1981.

Manson, A. H., C. E. Meek, M. Hagan, C. Hall, W. Hocking, J. MacDougall, S. Franke, D. Riggin, D. Fritts, R. Vincent, and M. Burrage, Seasonal variations of the semi-diurnal and diurnal tides in the MLT: Multi-year MF radar observations from 2 to $70^{\circ} \mathrm{N}$, and the GSWM tidal model, J. Atmos. Solar-Terr. Phys., 61, 809-828, 1999.

Mayr, H. G., J. G. Mengel, K. L. Chan, and H. S. Porter, Seasonal varia- tions of the diurnal tide induced by gravity wave filtering, Geophys. Res. Lett., 25, 943-946, 1998.

Mclandress, C., G. G. Shepherd, and B. H. Solheim, Satellite observations of thermospheric tides: Results from the Wind Imaging Interferometer on UARS, J. Geophys. Res., 101, 4093, 1996.

Nakamura, T., T. Tsuda, and S. Fukao, Mean winds at 60-90 km observed with the MU radar $\left(35^{\circ} \mathrm{N}\right)$, J. Atmos. Terr. Phys., 58, 655-660, 1996.

Namboothiri, S. P., T. Tsuda, and T. Nakamura, Interannual variability of mesospheric mean winds observed with the MU radar, J. Atmos. SolarTerr. Phys., 61, 1111-1122, 1999.

Namboothiri, S. P., P. Kishore, K. Igarashi, T. Nakamura, and T. Tsuda, MF radar observations of mean winds over Yamagawa $\left(31.2^{\circ} \mathrm{N}, 130.6^{\circ} \mathrm{E}\right)$ and Wakkanai $\left(45.4^{\circ} \mathrm{N}, 141.7^{\circ} \mathrm{E}\right)$, J. Atmos. Solar-Terr. Phys., 62, $1177-$ 1187,2000

Reddi, R. C., K. Rajeev, and G. Ramkumar, Tidal winds in the meteor region over Trivandrum, J. Atmos. Terr. Phys., 55, 1219-1231, 1993.

Roper, R. G., The measurement of meteor winds over Atlanta (34N, 84W), Radio Sci., 10, 363-369, 1975.

Tsuda, T. and S. Kato, Characteristics of semidiurnal tides observed by the Kyoto meteor radar and Saskatoon Medium-Frequency radar, $J$. Geophys. Res., 93, 7027-7036, 1988.

Tsuda, T., T. Nakamura, and S. Kato, Mean winds observed by the Kyoto meteor radar in 1983-1985, J. Atmos. Terr. Phys., 49, 461-466, 1987.

Vincent, R. A., T. Tsuda, and S. Kato, A comparative study of mesospheric solar tides observed at Adelaide and Kyoto, J. Geophys. Res., 93, 699708, 1988.

Vincent, R. A., S. Kovalam, D. C. Fritts, and J. R. Isler, Long-term MF radar observations of solar tides in the low-latitude mesosphere: Interannual variability and comparisons with the GSWM, J. Geophys. Res., 103, 8667-8683, 1998.

G. Zhao (e-mail: zhaogx@mail.igcas.ac.cn), L. Liu, W. Wan, B. Ning, and J. Xiong 